\title{
Índices de crescimento da cana-de-açúcar irrigada e de sequeiro no Estado da Paraíba
}

\author{
Carlos H. de A. Farias ${ }^{1}$, Pedro D. Fernandes ${ }^{2}$, Hamilton M. Azevedo ${ }^{2}$ \& José Dantas Neto ${ }^{2}$
}

\begin{abstract}
RESUMO
O experimento foi montado na Fazenda Capim II, situada na Cidade de Capim, PB, com o objetivo de se avaliar os índices de crescimento da parte aérea e do sistema radicular da variedade SP 791011 de cana-de-açúcar (Saccharum officinarum L.), em regime irrigado e de sequeiro. O delineamento estatístico foi o de blocos casualizados, em esquema fatorial $2 \times 6$, com três repetições, sendo realizadas seis amostragens de plantas e analisados os componentes da parte aérea e do sistema radicular. A taxa máxima de acúmulo de fitomassa foi de $0,7169 \mathrm{~g} \mathrm{dia}^{-1}$ para a cana irrigada e de 0,6974 $\mathrm{g} \mathrm{dia}^{-1}$ para a cana em regime de sequeiro. O máximo Índice de Área Foliar (IAF) foi 6,82, observado em torno dos 152 DAP em condições de irrigação; para a condição de sequeiro o IAF máximo foi de 6,80 aos 157 dias após o plantio. No final do período de cultivo, mais de 90 e de $80 \%$ da fitomassa de raízes se concentraram nos primeiros $60 \mathrm{~cm}$ de profundidade, nas áreas irrigadas e de sequeiro, respectivamente. $76 \%$ da fitomassa da raiz foram encontrados nos primeiros $45 \mathrm{~cm}$ de profundidade. O sistema de irrigação pode ser dimensionado tomando-se por base a profundidade de $60 \mathrm{~cm}$.
\end{abstract}

Palavras chave: Saccharum officinarum L., fitomassa, índice de área foliar, sistema radicular

\section{Growth indices of irrigated and non-irrigated sugar cane in Paraiba, Brazil}

\begin{abstract}
The experiment was conducted in the Capim II Farm, in the Capim municipality of Paraiba, with the objective of evaluating the growth indices of the aerial parts and the root system of variety SP 791011 of sugar cane (Saccharum officinarum L.) under irrigated and non-irrigated conditions. The statistical design adapted was a randomized blocks, in a $2 \times 6$ factorial scheme, with three replications, being six plants samplings made and the components of aerial part and root system analyzed. The dry mass accumulation maximum rate was $0.7169 \mathrm{~g} \mathrm{~d}^{-1}$ for irrigated sugar cane and $0.6974 \mathrm{~g} \mathrm{~d}^{-1}$ for sugar cane without irrigation. The maximum Leaf Area Index (LAI) was 6.82, observed around 152 days after planting (DAP) under irrigation; the LAI maximum without irrigation was 6.80 at 157 DAP. More than 90 and of $80 \%$ of root dry mass concentrated in the first $60 \mathrm{~cm}$ of depth, respectively, under irrigated and nonirrigated conditions. Around $76 \%$ of root dry mass was found in the first $45 \mathrm{~cm}$ of depth. The irrigation system can be designed taking as a base the depth of $60 \mathrm{~cm}$.
\end{abstract}

Key words: Saccharum officinarum L., dry mass, leaf area index, root system

1 Pesquisador da Destilaria Miriri S/A, DSc. em Recursos Naturais/UFCG, Fone: (83) 3292-2116. E-mail: carlos.henrique@miriri.com.br

2 UAEAg/UFCG, Fone: (83) 3310-1185. E-mail: pdantas@deag.ufcg.edu.br; hamilton@deag.ufcg.edu.br; zedantas@deag.ufcg.edu.br 


\section{INTRODUÇÃO}

A cultura da cana-de-açúcar teve sua expansão no Nordeste brasileiro no período de 1970 a 1975, com recursos do programa do álcool (Proálcool), principalmente nos tabuleiros costeiros, por se tratar de uma região mais favorecida por chuvas em determinados períodos do ano; entretanto a má distribuição e redução dos volumes de chuvas tem sido uma constante na região, nos últimos anos, trazendo prejuízos à cultura com a mortalidade de soqueiras, forçando uma renovação precoce do canavial.

Para satisfazer a capacidade de moagem das usinas de álcool e açúcar instaladas na região, as empresas estão investindo em novas tecnologias que proporcionem o aumento do rendimento da cultura. A irrigação complementar ou suplementar da cana-de-açúcar é, hoje, uma das alternativas tecnológicas em busca da verticalização da produção dessa cultura no Litoral Norte da Paraíba; no entanto, muitos produtores partem para a irrigação sem um planejamento adequado, sem considerar as necessidades hídricas, o manejo apropriado da água na cultura e sem conhecer as peculiaridades fisiológicas do crescimento da cana irrigada.

São escassos os resultados de pesquisas com cana-deaçúcar realizadas no Nordeste. Torna-se urgente, portanto, a execução de trabalhos que subsidiem os produtores de informações sobre o manejo eficiente de água na cultura. Os dados existentes no País foram obtidos, principalmente, em São Paulo (Barbieri et al., 1979; Carlucci \& Ramos, 1989; van den Berg et al., 2000; Alvarez et al., 2000). Dentre os tópicos de pesquisa, são fundamentais os que visem estudar os índices de crescimento, desenvolvimento e de produção.

O déficit hídrico afeta vários aspectos do crescimento vegetal; os efeitos mais óbvios do estresse hídrico se referem à redução do tamanho das plantas, de sua área foliar e da produtividade da cultura (Kramer, 1983; Taiz \& Zeiger, 2002). O grau de injúria causado pelo déficit hídrico depende consideravelmente do estádio fenológico em que ele ocorre na planta e da duração do estresse. Segundo Barlow et al. (1980), o crescimento vegetal depende da divisão celular, do crescimento e da diferenciação celular e todos esses processos são afetados por déficits hídricos, mas não necessariamente na mesma proporção.

Um efeito de particular importância em resposta a um déficit hídrico é a limitação à expansão da área foliar o decréscimo da área foliar é uma das conseqüências em resposta ao déficit hídrico, podendo ser considerado uma primeira linha de defesa contra a seca; o estresse hídrico não apenas limita o tamanho de cada folha mas, também, a área foliar pela diminuição no surgimento de novas folhas e pelo aumento da abscisão foliar (o estresse hídrico provoca uma síntese maior e uma maior sensibilidade ao hormônio etileno endógeno). Kramer (1983) cita que ocorre aumento da concentração de ácido abscísico com o estresse hídrico, com conseqüente aumento na taxa de queda de folhas.

Para Bull \& Glasziou (1975) em algumas variedades de cana-de-açúcar o dossel foliar entra em colapso e se torna senescente logo no início de uma seca, mas é capaz de rápida regeneração quando o estress hídrico é interrompido.

Segundo Irvine (1975) existe uma grande associação entre a produtividade da cultura e a superfície total fotossinteticamente ativa, representada pelo Índice de Área Foliar (IAF), intimamente associado à quantidade de luz absorvida e à fotossíntese total. Para Machado et al. (1985), ao ser interceptada pelo dossel foliar da cultura, a radiação solar pode ser absorvida, transmitida e refletida em proporções variáveis, dependendo do ângulo de incidência dos raios solares e das características estruturais das plantas.

Yassen \& Al-Omary (1994) relatam que a redução da área foliar devido ao estresse hídrico, pode ser atribuída principalmente à redução do número de células e à redução do volume celular. O decréscimo em ambos os processos, segundo os autores, é altamente significante, especialmente em condições de baixo potencial matricial do solo. Os autores também encontraram diferentes respostas em função dos diferentes estágios de crescimento.

A variação na distribuição relativa das raízes nas primeiras camadas do solo, na ausência de importantes impedimentos químicos e físicos, se deve à variação da umidade do solo (Inforzato \& Alvarez, 1957). Para os autores, o maior adensamento de raízes ocorre nos primeiros $30 \mathrm{~cm}$, com um percentual de 59\%. Ball-Coelho et al. (1992) observaram que $62,69 \%$ da matéria seca de raízes se situam nos primeiros $50 \mathrm{~cm}$ de profundidade e que entre 38 e $48 \%$ das raízes ativas estão nos primeiros $30 \mathrm{~cm}$ superficiais.

Van den Berg et al. (2000), estudando o rendimento potencial da cana-de-açúcar no Estado de São Paulo, demonstram que quanto maior o volume de raízes por camada, maior é, também, o rendimento potencial da cultura, tanto para cana planta como para cana soca. Os autores afirmam que o rendimento tende a aumentar com o aumento do volume de raízes.

Diante deste contexto, o objetivo desta pesquisa foi avaliar o crescimento da cultura da cana-de-açúcar, parte aérea e raízes, em condições de irrigação e de sequeiro, em tabuleiro costeiro paraibano.

\section{MATERIAL E MÉTODOS}

O experimento foi conduzido na Fazenda Capim II (latitude $6^{\circ} 54^{\prime} 59,88^{\prime}$ ' S, longitude $35^{\circ} 09^{\prime} 17,86^{\prime}$ ' O e altitude de $121 \mathrm{~m}$ ), localizada no município de Capim, PB. A fazenda se situa na bacia hidrográfica do Rio Miriri, cuja área de drenagem mede cerca de $436,50 \mathrm{~km}^{2}$. O experimento foi montado em uma área total de 3,50 ha, sendo 1,30 ha irrigados e 2,20 ha em condições de sequeiro, utilizando-se a variedade SP 791011 de cana-de-açúcar. $\mathrm{O}$ trabalho se constituiu de dois fatores, sendo o primeiro a condição de umidade do solo (U) e o segundo a época de avaliação (E), durante o ciclo da cultura, constituindo um fatorial $2 \times 6$, no delineamento estatístico de blocos casualizados. 
O solo da fazenda é classificado como uma associação de Latossolo Vermelho Amarelo, com presença de fragipam e Latossolo Vermelho Amarelo, Latossólico, ambos de textura média. As características físico-hídricas e químicas do solo estão apresentadas na Tabela 1.

O plantio foi realizado em 05 de fevereiro de 2000; a cana foi semeada com rebolos de aproximadamente $45 \mathrm{~cm}$, em uma profundidade de $30 \mathrm{~cm}$, mantendo-se o espaçamento de $1,20 \mathrm{~m}$ entre fileiras.

Aplicou-se na fundação apenas o super fosfato simples na quantidade de $90,00 \mathrm{~kg}$ de $\mathrm{P}_{2} \mathrm{O}_{5}$ e em cobertura $67,50 \mathrm{~kg} \mathrm{ha}^{-1}$ de nitrogênio e $120,00 \mathrm{~kg} \mathrm{ha}^{-1}$ de $\mathrm{K}_{2} \mathrm{O}$, dos produtos comerciais uréia e coreto de potássio, respectivamente.

Tabela 1. Análise físico-hídrica do solo das áreas estudadas com a cultura da cana-de-açúcar, Fazenda Capim II, Capim, PB, 2000

\begin{tabular}{|c|c|c|c|c|c|}
\hline \multirow{2}{*}{ Variável } & \multicolumn{5}{|c|}{ Profundidade (cm) } \\
\hline & $0-20$ & $21-40$ & $41-60$ & $61-80$ & $81-100$ \\
\hline \multicolumn{6}{|l|}{ Granulometria (\%) } \\
\hline Areia & 54,14 & 60,15 & 47,09 & 30,06 & 31,56 \\
\hline Silte & 6,01 & 4,01 & 7,02 & 20,04 & 15,15 \\
\hline Argila & 39,85 & 35,84 & 45,89 & 49,90 & 53,29 \\
\hline \multicolumn{6}{|l|}{ Textura* } \\
\hline \multicolumn{6}{|c|}{ Densidade $\left(\mathrm{g} \mathrm{cm}^{-3}\right)$} \\
\hline Aparente & 1,65 & 1,63 & 1,65 & 1,72 & 1,66 \\
\hline Real & 2,64 & 2,78 & 2,74 & 2,70 & 2,77 \\
\hline Porosidade (\%) & 37,5 & 41,36 & 39,78 & 36,29 & 40,07 \\
\hline \multicolumn{5}{|l|}{ Umidade (\%) } & 1,52 \\
\hline $0,33 \mathrm{~atm}$ & 10,59 & 11,19 & 17,74 & 17,09 & 20,36 \\
\hline $15,00 \mathrm{~atm}$ & 7,83 & 8,48 & 13,03 & 12,80 & 15,22 \\
\hline Água disponível & 2,76 & 2,71 & 4,71 & 4,29 & 5,14 \\
\hline Cálcio & 0,07 & 0,14 & 0,07 & 0,06 & 0,07 \\
\hline Magnésio & 0,54 & 1,01 & 0,33 & 0,39 & 0,50 \\
\hline Sódio & 0,08 & 0,12 & 0,05 & 0,07 & 0,07 \\
\hline Potássio & 0,08 & 0,12 & 0,03 & 0,03 & 0,03 \\
\hline Somatório & 0,78 & 1,39 & 0,47 & 0,55 & 0,66 \\
\hline Hidrogênio & 6,01 & 14,31 & 8,83 & 7,20 & 4,84 \\
\hline Alumínio & 0,19 & 0,14 & 0,18 & 0,15 & 0,18 \\
\hline $\mathrm{pH}$ & 4,58 & 4,48 & 4,44 & 4,67 & 4,69 \\
\hline CE mmos/cm & 0,10 & 0,16 & 0,07 & 0,07 & 0,06 \\
\hline pHes & 4,18 & 4,20 & 4,36 & 4,63 & 4,76 \\
\hline CEes mmos/cm & 0,34 & 0,85 & 1,21 & 0,23 & 0,42 \\
\hline Cloreto & 2,00 & 4,20 & 2,00 & 2,60 & 1,85 \\
\hline Carbonato & Aus & Aus & Aus & Aus & Aus \\
\hline Bicarbonato & 0,50 & 0,32 & 0,60 & 0,38 & 0,52 \\
\hline Sulfato & Aus & Aus & Aus & Aus & Aus \\
\hline Cálcio & 1,08 & 1,25 & 0,68 & 0,75 & 0,68 \\
\hline Magnésio & 1,73 & 5,75 & 2,35 & 1,73 & 1,45 \\
\hline Potássio & 0,03 & 0,06 & 0,01 & 0,01 & 0,01 \\
\hline Sódio & 0,09 & 0,17 & 0,07 & 0,11 & 0,09 \\
\hline & 24,67 & 24,00 & 29,07 & 33,33 & 40,00 \\
\hline
\end{tabular}

* AA - Argila arenosa, $A$ - Argila
Para o controle de ervas daninhas na cultura se aplicou o herbicida 2,4-D ( $\left.2 \mathrm{~L} \mathrm{ha}^{-1}\right)$ e se coletaram, durante o período experimental todos os volumes precipitados em uma estação de observação localizada a 200 m do talhão experimental.

As irrigações foram realizadas a cada 12 dias, conforme o projeto hidráulico do sistema; no entanto, devido ao elevado índice de precipitação do ano 2000, as irrigações foram executadas somente quando se considerou que a precipitação não era suficiente para repor a umidade do solo apropriada à cultura, pelo período de 12 dias (turno de irrigação previsto).

As amostragens de plantas ocorreram aos 30, 60, 98, 171, 246 e 280 dias após o plantio (DAP). A amostra do tipo destrutiva consistiu de todas as plantas contidas em $1,50 \mathrm{~m}$ de fileira em seis repetições com espaçamento entre linhas de $1,20 \mathrm{~m}$, totalizando uma área de $10,80 \mathrm{~m}^{2}$ por amostragem. Do total de plantas colhidas utilizou-se uma sub-amostra de dez plantas, de forma aleatória, para as seguintes determinações dos parâmetros da parte aérea: perfilhamento, altura de plantas, fitomassa seca do colmo e de raízes e área foliar.

Utilizaram-se, na determinação da área foliar, perfuradores com diâmetro de 20, 13 e $9 \mathrm{~mm}$, se relacionando, através do método gravimétrico, a área dos círculos com seus respectivos pesos de fitomassa seca com o peso da fitomassa seca do restante da folha, obtendo-se, assim, a área foliar de cada folha fotossinteticamente ativa.

Os dados coletados para análise do crescimento radicular foram oriundos de coletas nas duas áreas (irrigada e de sequeiro) nos períodos correspondentes a 30,60, 98, 171, 246 e 280 DAP. Utilizou-se um trado especial (rootauger) para coletas de solo e raízes, com copo coletor de $15,0 \mathrm{~cm}$ de altura e 7,5 cm de diâmetro. Em cada amostragem foi explorada uma área de $1 \mathrm{~m}^{2}$, entre duas fileiras, nas três repetições. A área amostrada $\left(1 \mathrm{~m}^{2}\right)$ foi dividida em quadrículas de $20,0 \mathrm{~cm}$ no sentido paralelo à fileira e nas distâncias de $15,35,50,65$ e $85 \mathrm{~cm}$, no sentido perpendicular às fileiras de plantas. As profundidades de coletas foram: $0-15 ; 16-30 ; 31-45 ; 46-60 ; 61-75$ e $76-90 \mathrm{~cm}$, totalizando 540 amostras para cada tratamento estudado. Após a coleta, se procedeu, em laboratório, a lavagem do solo e separação das raízes com peneiras de malha de dois milímetros submetendo-se, em seguida, as amostras de raízes, devidamente acondicionadas em sacos de papel, à secagem em estufa de circulação forçada de ar a $65^{\circ} \mathrm{C}$ por $120 \mathrm{~h}$.

A lâmina bruta de água incidida sobre a cultura no ano de 2000 consiste na precipitação total bruta mais a lâmina total bruta de irrigação, dados expostos na Tabela 2. O equipamento de irrigação foi tipo pivô central retocável de 46,00 ha da marca Irrigabras ${ }^{\circledR}$.

Tabela 2. Lâmina bruta (mm) incidida na cana 'SP 79 1011' durante o período experimental

\begin{tabular}{ccccccccccccccc}
\hline & Jan & Fev & Mar & Abr & Mai & Jun & Jul & Ago & Set & Out & Nov & Dez & TotaL \\
Prec. & 120 & 105,5 & 79,5 & 210 & 129,5 & 611 & 310 & 192 & 256,5 & 2,5 & 33 & 495 & $2.544,5$ \\
Irrigação & 32 & 64 & 80 & 0 & 0 & 0 & 0 & 0 & 0 & 80 & 80 & 80 & 416 \\
\hline
\end{tabular}




\section{RESULTADOS E DISCUSSÃO}

\section{Análise morfofisiológica da parte aérea}

Tem-se na Figura 1A, o comportamento da cultura em altura, ao longo do tempo, quando cultivada em sistema irrigado e de sequeiro. Observa-se efeito significativo a $5 \%$ para os coeficientes das equações (Tabela 3). Para a canade-açúcar cultivada em sistema irrigado, o ponto de máxima é atingido aos 193,85 dias com altura máxima de $152,80 \mathrm{~cm}$. A taxa de crescimento em altura é neste caso, até os 280 dias, de $0,5457 \mathrm{~cm} \mathrm{~d}^{-1}$.

Na Figura 1A também está ilustrado o comportamento da cultura quando cultivada em sequeiro. Observa-se que os coeficientes da equação (Tabela 3 ) foram estatisticamente significantes. Para a cultura cultivada nesse sistema de manejo, o máximo em altura é atingido aos 236,20 dias, ponto no qual a altura máxima atingida é de $148,19 \mathrm{~cm}$; a taxa de crescimento em altura para a cana de sequeiro é de $0,5292 \mathrm{~cm} \mathrm{dia}^{-1}$ até os 280 dias após o plantio.

$\mathrm{Na}$ Figura 1B está exposto o comportamento da cana 'SP 79 1011' em relação ao acúmulo de fitomassa ao longo do tempo, para os dois manejos estudados. Observa-se efei-

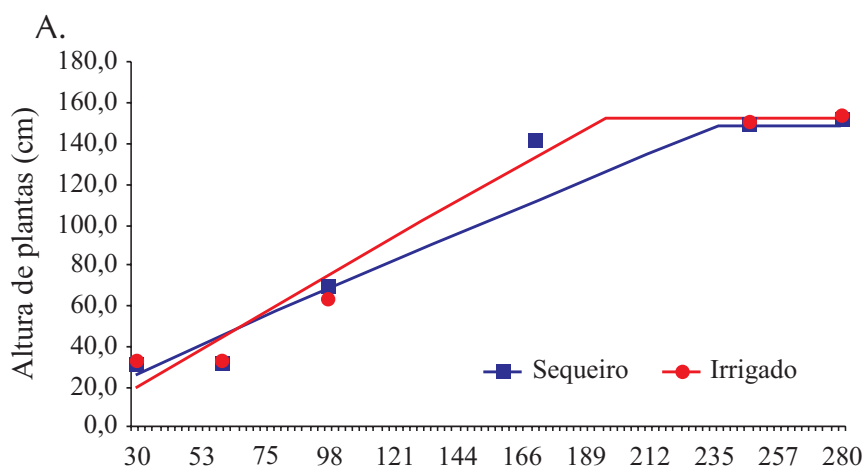

B.

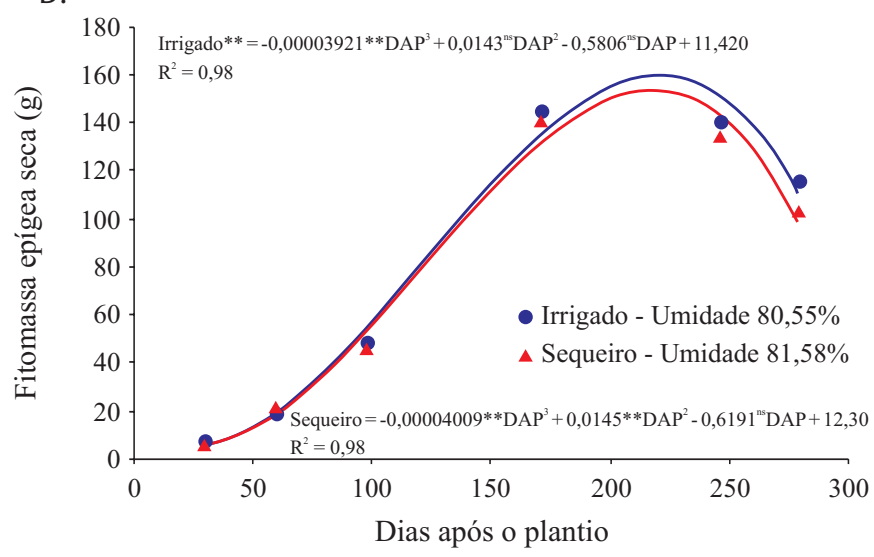

Figura 1. (A) Altura de planta irrigada e de sequeiro curva de regressão em platô; (B) Fitomassa epígea seca para a cana 'SP 79 1011' to estatisticamente significativo para os coeficientes das equações. Extraindo-se a primeira derivada do modelo para a cana irrigada é possível perceber que o ponto de máximo é atingido aos 220,77 dias, momento em que a fitomassa máxima acumulada é de $158,31 \mathrm{~g}$. A taxa de acúmulo de fitomassa nesse ponto é de $0,7169 \mathrm{~g} \mathrm{~d}^{-1}$.

Da mesma forma, para a cana de sequeiro o modelo tem o ponto de máximo aos 217,45 dias, com acúmulo máximo de fitomassa epígea de 151,10 g e taxa de acúmulo da cultura de $0,6974 \mathrm{~g} \mathrm{~d}^{-1}$.

A área foliar variou de forma crescente e significativa ao longo do período de cultivo, haja vista que se observou efeito significativo dos coeficientes dos modelos para os dois sistemas de cultivo estudados (Figura 2A). Nota-se, através da determinação dos pontos de máximo do modelo, que para a cana de sequeiro a área foliar máxima é 5.168,04 dm², aos 166,68 dias, ou seja, uma taxa de crescimento nesse ponto, de $31,00 \mathrm{dm}^{2} \mathrm{~d}^{-1}$. A cana cultivada em regime irrigado atingiu o ponto de máxima área foliar $\left(5.359,65 \mathrm{dm}^{2}\right)$ aos 152,63 dias, com taxa de crescimento foliar de $35,11 \mathrm{dm}^{2} \mathrm{~d}^{-1}$.

Tem-se, na Figura 2B, o comportamento da cultura quanto ao Índice de Área Foliar (IAF). O IAF máximo para a cana irrigada foi observado aos 151,70 dias após o

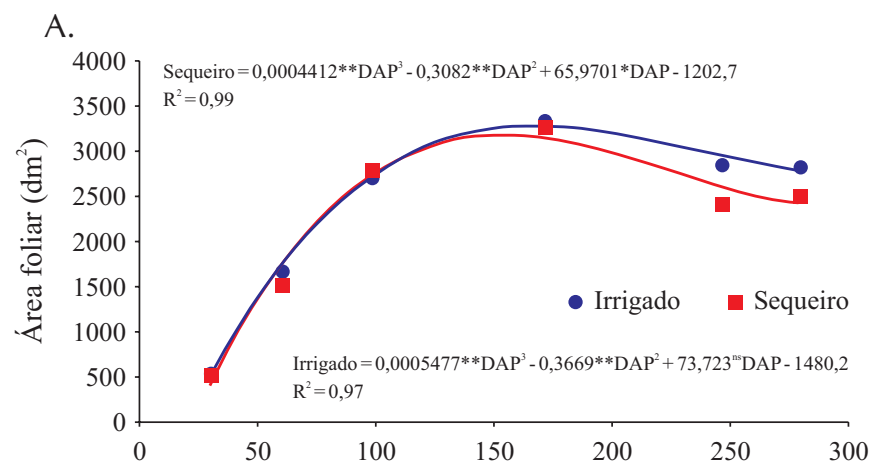

B.

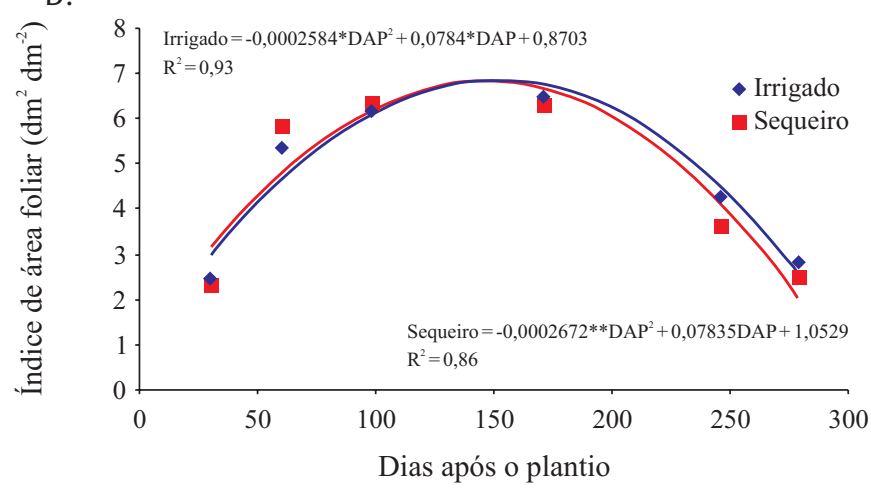

Figura 2. (A) Área foliar; (B) Índice de Área Foliar (IAF) para a cana 'SP 79 1011' irrigada e de sequeiro

Tabela 3. Resumo da análise de variância da regressão em platô para a altura de plantas da cana 'SP 79 1011' Fazenda Capim II, Capim, PB, 2000

\begin{tabular}{|c|c|c|c|c|}
\hline \multirow{2}{*}{ Fonte de variação } & \multicolumn{4}{|c|}{ Estudo de regressão (Linear response plateau) } \\
\hline & Modelo & QMDR & $\mathbf{F}$ & Prob $F$ \\
\hline Irrigado & 0,8137*DAP - 4,9570; $R^{2}=0,93: E R^{*}=193,85$ dias, $152,80 \mathrm{~cm}$ & 7367,29 & 30,46 & 0,0313 \\
\hline Sequeiro & $0,5947{ }^{\star} \mathrm{DAP}+7,7051 ; \mathrm{R}^{2}=0,82: \mathrm{ER}^{\star}=236,20$ dias, $148,19 \mathrm{~cm}$ & 7821,61 & 34,73 & 0,0274 \\
\hline
\end{tabular}

* ER - encontro das retas 
plantio, quando ela atingiu o valor de $6,82 \mathrm{dm}^{2} \mathrm{dm}^{-2}$; na condição de sequeiro, o máximo $\operatorname{IAF}\left(6,80 \mathrm{dm}^{2} \mathrm{dm}^{-2}\right)$ foi obtido aos 146,61 dias após o plantio. Os resultados aqui encontrados diferem dos valores citados para a cultura, por Machado (1981) e Robertson et al. (1999); no entanto estão mais próximos dos valores verificados por Chang (1968) de 9,00 a 12,00 e de 7,60 registrado por San José \& Medina (1970).

\section{Análise do sistema radicular}

A quantidade total média de raízes no final do período amostrado ( $6^{\mathrm{a}}$ coleta), comparando-se os dois tratamentos, foi de $34,74 \mathrm{~g}$ para a cana irrigada e de $40,92 \mathrm{~g}$ para a cana de sequeiro (Tabela 3).

Quando comparados os dois tratamentos, não se pode afirmar estatisticamente que a percentagem de raízes da cana irrigada na superfície do solo seja significativamente maior que na cana de sequeiro; da mesma forma, a comparação entre a quantidade de raízes de cana irrigada e de sequeiro, nas seis profundidades, evidencia que em profundidades maiores também não há diferenças estatísticas entre os tratamentos.

No experimento, a maior percentagem de raízes no solo se encontra nas camadas mais superficiais para os dois tratamentos ao longo do período de cultivo. Diferenças signifi- cativas entre as médias dos manejos, ocorreram na profundidade de 0 a $15 \mathrm{~cm}$ e 16 a $30 \mathrm{~cm}$ aos 60 DAP. Quando irrigada, a cultura emite mais rapidamente o seu sistema radicular, de forma tal que na primeira camada, a mais úmida, o sistema se encontra ainda superficial com um volume maior de raiz na superfície que na de sequeiro; no entanto, na área de sequeiro, o sistema radicular aprofundou-se de forma tal que apresentou maior massa na camada de 16 a $30 \mathrm{~cm}$, enquanto a maior quantidade de raízes no solo se encontra nas camadas mais superficiais para os dois manejos.

Pode-se observar ao longo do tempo, que a percentagem de matéria seca de raízes se apresentou como significativamente diferente nos manejos estudados. Diferença significativa ocorreu também na profundidade de 76 a $90 \mathrm{~cm}$ aos 246 dias, com crescimento maior do sistema radicular da cana cultivada em regime de sequeiro.

Na Figura 3A está graficamente ilustrado o perfil de distribuição do sistema radicular no solo por camada (0-15; 16-30; 31-45; 46-60; 61-75 e de 76-90 cm). A proporção de raízes foi quantificada em relação à quantidade total no perfil do solo estudado. No perfil do sistema radicular exposto na Tabela 2, pode-se observar que as raízes se concentraram, em maior quantidade, nas camadas mais superficiais do solo.

Observando-se todo o comportamento do crescimento radicular da cultura da cana-de-açúcar, nota-se que o padrão

Tabela 4. Porcentagem de raízes e peso de matéria seca (g) da cana de açúcar ao longo do ciclo, em seis coletas e seis profundidades, para os dois tratamentos estudados Fazenda Capim II, Capim, PB, 2000

\begin{tabular}{|c|c|c|c|c|c|c|c|c|c|c|c|}
\hline \multirow{2}{*}{ Perfil (cm) } & \multirow{2}{*}{ Trat. } & \multicolumn{6}{|c|}{ Dias após o plantio } & \multirow{2}{*}{ QMR } & \multirow{2}{*}{ QMP } & \multirow{2}{*}{$\begin{array}{l}\text { QM } \\
\text { RxP }\end{array}$} & \multirow{2}{*}{$\begin{array}{l}\mathrm{CV} \\
\%\end{array}$} \\
\hline & & 30 & 60 & 98 & 171 & 246 & 280 & & & & \\
\hline \multirow{2}{*}{$0-15$} & I & $\begin{array}{l}100 \mathrm{Aa} \\
(1,69)^{0}\end{array}$ & $\begin{array}{c}56,05 \mathrm{Ba} \\
(6,23)\end{array}$ & $\begin{array}{c}43,31 \mathrm{Ca} \\
(7,12)\end{array}$ & $\begin{array}{c}42,25 \mathrm{Ca} \\
(14,76)\end{array}$ & $\begin{array}{c}36,85 \mathrm{Ca} \\
(13,99)\end{array}$ & $\begin{array}{c}32,09 \mathrm{Da} \\
(10,96)\end{array}$ & \multirow{2}{*}{$83,29 *$} & \multirow{2}{*}{$3935,15^{\star *}$} & \multirow{2}{*}{$27,88 \mathrm{~ns}$} & \multirow{2}{*}{8.49} \\
\hline & S & $\begin{array}{c}100 \mathrm{Aa} \\
(0,88)\end{array}$ & $\begin{array}{c}52,75 \mathrm{Bb} \\
(5,84)\end{array}$ & $\begin{array}{c}38,49 \mathrm{Cb} \\
(4,65)\end{array}$ & $\begin{array}{c}42,60 \mathrm{Ca} \\
(11,35)\end{array}$ & $\begin{array}{c}32,64 \mathrm{Ca} \\
(12,08)\end{array}$ & $\begin{array}{c}32,31 \mathrm{Da} \\
(13,25)\end{array}$ & & & & \\
\hline \multirow{2}{*}{$16-30$} & I & - & $\begin{array}{c}43,95 \mathrm{Ab} \\
(4,89)\end{array}$ & $\begin{array}{c}32,81 \mathrm{Ba} \\
(5,39)\end{array}$ & $\begin{array}{c}22,84 \mathrm{Ca} \\
(7,98)\end{array}$ & $\begin{array}{c}22,25 \mathrm{Ca} \\
(8,45)\end{array}$ & $\begin{array}{c}23,58 \mathrm{Ca} \\
(8,05)\end{array}$ & \multirow[b]{2}{*}{ 4,78ns } & \multirow[b]{2}{*}{$1382,09 * *$} & \multirow[b]{2}{*}{ 1,47ns } & \multirow[b]{2}{*}{9,34} \\
\hline & S & - & $\begin{array}{c}47,25 \mathrm{Aa} \\
(5,23)\end{array}$ & $\begin{array}{c}35,54 \mathrm{Ba} \\
(4,31)\end{array}$ & $\begin{array}{c}19,98 \mathrm{Ca} \\
(5,33)\end{array}$ & $\begin{array}{c}23,81 \mathrm{Ca} \\
(8,83)\end{array}$ & $\begin{array}{c}23,51 \mathrm{Ca} \\
(9,64)\end{array}$ & & & & \\
\hline \multirow{2}{*}{$31-45$} & I & - & - & $\begin{array}{c}23,84 \mathrm{Aa} \\
(3,92)\end{array}$ & $\begin{array}{c}17,86 \mathrm{Ba} \\
(6,24)\end{array}$ & $\begin{array}{c}18,25 \mathrm{Ba} \\
(6,93)\end{array}$ & $\begin{array}{c}20,08 \mathrm{Ba} \\
(6,86)\end{array}$ & \multirow{2}{*}{ 7,53ns } & \multirow{2}{*}{731,26 ** } & \multirow{2}{*}{$6,43 \mathrm{~ns}$} & \multirow{2}{*}{14,66} \\
\hline & $\mathrm{S}$ & - & - & $\begin{array}{c}28,62 \mathrm{Aa} \\
(3,47)\end{array}$ & $\begin{array}{c}17,01 \mathrm{Ba} \\
(4,54)\end{array}$ & $\begin{array}{c}20,04 \mathrm{Ba} \\
(7,41)\end{array}$ & $\begin{array}{c}19,26 \mathrm{Ba} \\
(7,90)\end{array}$ & & & & \\
\hline \multirow{2}{*}{$46-60$} & I & - & - & - & $\begin{array}{c}11,59 \mathrm{Aa} \\
(4,05)\end{array}$ & $\begin{array}{c}11,80 \mathrm{Aa} \\
(4,48)\end{array}$ & $\begin{array}{c}12,06 \mathrm{Aa} \\
(4,11)\end{array}$ & \multirow{2}{*}{$1,22 \mathrm{~ns}$} & \multirow{2}{*}{281,41 ** } & \multirow{2}{*}{ 1,62ns } & \multirow{2}{*}{13,62} \\
\hline & S & - & - & - & $\begin{array}{c}13,86 \mathrm{Aa} \\
(3,70)\end{array}$ & $\begin{array}{c}12,58 \mathrm{Aa} \\
(4,65)\end{array}$ & $\begin{array}{c}12,42 \mathrm{Aa} \\
(5,01)\end{array}$ & & & & \\
\hline \multirow{2}{*}{$61-75$} & I & - & - & - & $\begin{array}{c}5,46 \mathrm{Aa} \\
(1,91)\end{array}$ & $\begin{array}{c}9,16 \mathrm{Aa} \\
(3,47)\end{array}$ & $\begin{array}{c}8,99 \mathrm{Ba} \\
(3,67)\end{array}$ & \multirow{2}{*}{$0,06 \mathrm{~ns}$} & \multirow{2}{*}{120,91 ** } & \multirow{2}{*}{$0,39 \mathrm{~ns}$} & \multirow{2}{*}{16,23} \\
\hline & $\mathrm{S}$ & - & - & - & $\begin{array}{c}6,55 \mathrm{Aa} \\
(1,75)\end{array}$ & $\begin{array}{c}8,82 \mathrm{Aa} \\
(3,26)\end{array}$ & $\begin{array}{c}8,76 \mathrm{Aa} \\
(3,59)\end{array}$ & & & & \\
\hline \multirow{2}{*}{$76-90$} & I & - & - & - & - & $\begin{array}{c}1,69 \mathrm{Bb} \\
(0,64)\end{array}$ & $\begin{array}{c}3,20 \mathrm{Aa} \\
(1,09)\end{array}$ & \multirow{2}{*}{$0,13 \mathrm{~ns}$} & \multirow{2}{*}{12,30 ** } & & \\
\hline & $\mathrm{S}$ & - & - & - & - & $\begin{array}{c}2,06 \mathrm{Ba} \\
(0,76)\end{array}$ & $\begin{array}{c}3,74 \mathrm{Aa} \\
(1,53)\end{array}$ & & & 0,05ns & 55,96 \\
\hline Total de & I & 1,69 & 11,12 & 16,43 & 34,94 & 37,96 & 34,74 & & & & \\
\hline raízes (g) & $S$ & 0,88 & 11,07 & 12,43 & 26,67 & 36,99 & 40,92 & & & & \\
\hline
\end{tabular}

Letras maiúsculas na mesma linha e minúscula na mesma coluna (na mesma profundidade e mesmo tratamento) não diferem entre si; l-irrigado, S-sequeiro; ns não significativo; * significativo a 1\% e ** $5 \%$ de probabilidade; ${ }^{\circ}$ entre parênteses estão os dados correspondentes, em gramas de raízes; QMR: quadrado médio para regime; QMP: quadrado médio para período; QMRP: quadrado médio para interação entre os fatores; CV - coeficiente de variação 
A.

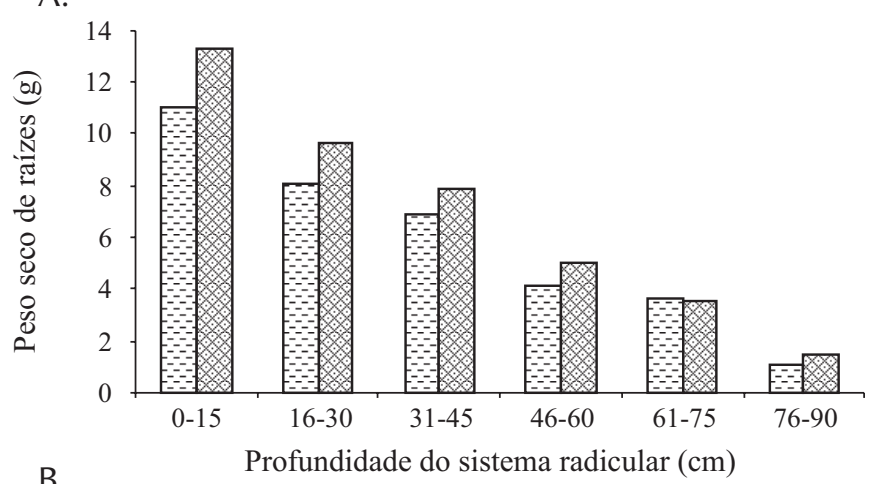

B.

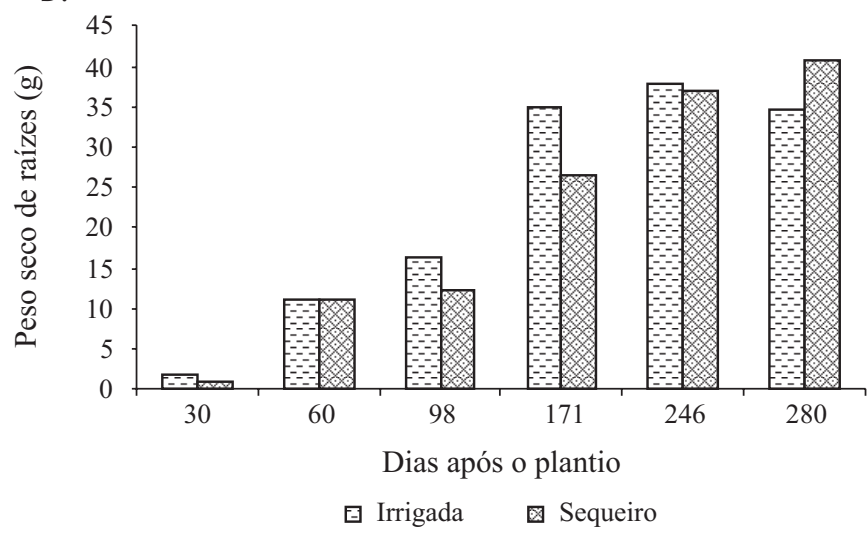

Figura 3. Perfis de distribuição do sistema radicular aos 280 dias após o plantio (A), de crescimento do sistema radicular ao longo do tempo (B), para a cana 'SP $791011^{\prime}$ irrigada e de sequeiro

de crescimento das raízes da cana 'SP 79 1011' começa a se definir nos primeiros dias do ciclo; aos 30 DAP, o sistema radicular ainda não está bem desenvolvido e, portanto, se formando, em virtude de que $100 \%$ das raízes para os dois tratamentos estavam localizados nos primeiros $15,00 \mathrm{~cm}$ de profundidade; aos 60 DAP, a $15 \mathrm{~cm}$ de profundidade se encontra 56,05 e $52,75 \%$ do total de raízes estimadas; aos 98 DAP a cultura está com $76,12 \%$ das raízes nos primeiros $30 \mathrm{~cm}$ de profundidade para a cana irrigada, enquanto para a cana em regime de sequeiro e nessa mesma profundidade, foram encontrados $74,03 \%$ do total de raízes estimadas.

A partir dos 171 DAP, o sistema radicular da cultura se encontra na profundidade de até $75,00 \mathrm{~cm}$; no entanto, nesse mesmo período 82,95 e $79,59 \%$ das raízes se concentram nos primeiros $45 \mathrm{~cm}$ de profundidade para a cana irrigada e de sequeiro, respectivamente.

Decorridos 246 dias após o plantio e embora se tenha encontrado raízes até os $90,00 \mathrm{~cm}$ de profundidade, $77,35 \%$ do sistema radicular da cultura se encontraram nos primeiros $45 \mathrm{~cm}$ para a cana irrigada e $76,49 \%$ para a cana de sequeiro. Na última coleta de dados (280 DAP), 87,81\% do total das raízes da cana irrigada estavam nos primeiros $60 \mathrm{~cm}$ de profundidade; para o cultivo de sequeiro, a massa de raízes, no mesmo período e na mesma profundidade, representa $87,50 \%$ do total estimado. Os resultados obtidos estão de acordo com os indicados por Inforzato \& Alvarez (1957), Sampaio et al. (1987), Ball \& Coelho (1992) e Alvarez et al. (2000).
Para Inforzato \& Alvarez (1957), 59,00\% do sistema radicular, ao final do ciclo, encontram-se nos primeiros $30 \mathrm{~cm}$ de profundidade. Ball-Coelho et al. (1992) observaram $62,69 \%$ do sistema radicular nos $50 \mathrm{~cm}$ superficiais do solo.

Alvarez et al. (2000), trabalhando com cana crua e queimada, afirmam que na cana crua o sistema radicular se distribui nos primeiros $40 \mathrm{~cm}$ de solo com $75 \%$ do total; no mesmo trabalho e para a cana queimada, $72 \%$ do sistema radicular estavam nos primeiros $40 \mathrm{~cm}$ de profundidade; em estudo realizado no segundo ano, esses valores são 70 e $68 \%$ para a cana crua e queimada, respectivamente.

Uma concentração maior de raízes na superfície favorece uma absorção maior da água após irrigação ou precipitação, minimizando a evaporação, também defendido por Lampurlanés et al. (2001). Segundo os autores, a alta densidade de raízes nas camadas superficiais é uma característica favorável à absorção de água, após irrigações ou chuvas, minimizando a evaporação.

\section{CONCLUSÕES}

1. O IAF máximo da cana irrigada para a região é de 6,82 , enquanto para a cultura de sequeiro é de 6,80 .

2. Aos 193,85 dias é estabilizado o crescimento da cana irrigada em 152,80 cm. A cana de sequeiro estabiliza seu crescimento em altura aos 236,20 dias, com 148,19 cm.

3 . No final do período de cultivo (280 DAP), a concentração da fitomassa de raízes nos primeiros $60 \mathrm{~cm}$ de profundidade é superior a $90 \%$ no cultivo irrigado e $80 \%$ no de sequeiro e, de forma geral, $75 \%$ das raízes se encontram nos primeiros $45 \mathrm{~cm}$ de profundidade.

\section{AGRADECIMENTOS}

À Destilaria Miriri S.A., pela busca incessante do conhecimento e pelo incentivo à ciência e à tecnologia na região Nordeste. Ao seu Diretor superintendente Dr. Gilvan Celso Cavalcante de Morais Sobrinho, e seu Gerente Agrícola, Dr. Gabriel Saturnino de Oliveira.

\section{LITERATURA CITADA}

Alvarez, I. A.; Castro, P. R. de C.; Nogueira, M. C. S. Crescimento de raízes de cana crua e queimada em dois ciclos. Scientia Agricola, v.57, n.4, p.653-659, 2000.

Ball-Coelho, B.; Sampaio, E. U. S. B.; Tiessen, H.; Stwartj, W. B. Root dynamics in plant ratoon crops of sugar cane. Plant and Soil, v.42, p.297-305, 1992.

Barbieri, V; Bacchi, O. O. S.; Villa Nova, N. A. Análise do fator temperatura média do ar no desenvolvimento vegetativo da cana-de-açúcar (Saccharum spp). Mossoró, ESAM, 1979 In: Congresso Brasileiro de Agrometeorologia, 1, 1979, Mossoró. Anais... Mossoró: SBA, v.1. p.6-8, 1979.

R. Bras. Eng. Agríc. Ambiental, v.12, n.4, p.356-362, 2008. 
Barlow, E. W. R.; Munns, R. E.; Brady, L. J. Drought responses of apical meristems. In: Turner, N. C.; Kramer, P. J. (eds.). Adaptation of plants to water and high temperature stress. New York: Wiley, p.191-205. 1980

Bull, T. A.; Glasziou, K. T. Sugar cane. In: Evans, L. T. (ed.). Crop physiology: Some case histories. Cambridge: University Press, 1975, cap. 3, p.51-72.

Carlucci, M. V.; Ramos, M. T. B. Influência da deficiência hídrica no florescimento e características tecnológicas da cana-de-açúcar. Pesquisa Agropecuária Brasileira, v.24, n.4, p.461-466, 1989.

Chang, J. Climate and agricrop: an ecological survey. Chicago: Aldine, 1968, 304p.

Inforzato, R.; Alvarez, R. Distribuição do sistema radicular da canade-açúcar var. 290, em solo tipo terra roxa legitima. Bragantia, v.16, p.1-13, 1957.

Irvine, J. E. Relations of photosynthetic rates and leaf and canopy characters to sugarcane yield. Crop Science, v. 15 p. 671-676, 1975

Kramer, P. J. Water relations of plants. New York: Academic Press, 1983. 489p.

Lampurlanés, J.; Angás, J.; Cantero-Martinez, C. Root growth, soil water content and yield of barley under different tillage system on two soil in semiarid conditions. Field Crop Research. Elsevier. v.69 p.27-40, 2001.
Machado, E. C. Um modelo matemático-fisiológico para simular o acúmulo de matéria-seca na cultura da cana-de-açúcar (Saccharum spp). Campinas: UNICAMP 1981, 115p. Dissertação Mestrado

Machado, E. C.; Pereira. A. R.; Camargo, M. B. P.; Gahl, J. I. Relações radiométricas de uma cultura de cana-de-açúcar. Bragantia, v.44 n.1 p.229-238, 1985.

Robertson, M. J.; Inmam-Bamber, N. G.; Muchow, R. C.; Wood, A. W. Physiology and productivity of sugar cane with early and midseason water deficit. Field Crop Research, v.64, p.211-227, 1999.

Sampaio, E. V. S. B.; Salcedo, J. H.; Cavalcante, F. J. H. Dinâmica de nutrientes em cana-de-açúcar: III Conteúdo de nutrientes e distribuição do sistema radicular no solo. Pesquisa Agropecuária Brasileira, v.22, p.425-431, 1987.

San José, J. J.; Medina, E. Análisis de la productividad de caña de azúcar. I. Crecimiento, desarrollo de la superficie foliar y contenido de clorofila de caña de azúcar 'PR 980'. Turrialba, v.20, n.2, p.143-8, 1970.

Taiz, L.; Zeiger, E. Plant physiology. 3.ed. Sunderland: Sinauer Associates, 2002. 798p.

Yassen, B. T.; Al-Omary, S. S. Analysis of the effects of water stress on leaf growth and yield of three barley cultivars. Irrigation Science, v.14 p.157-162, 1994.

van den Berg, M.; Burrough, P. A.; Driessen, P. M. Uncertainties in the appraisal of water availability and consequences for simulated sugar cane yield potentials in São Paulo State, Brazil. Agricrop Ecosystems; Environment, v.81, p.43-55, 2000. 